\title{
BIBLIOTECA UNIVERSITÁRIA COMO MEDIADORA NA PRODUÇÃO DE CONHECIMENTO
}

\author{
University library as a mediator in \\ the production of knowledge
}

\author{
Heloisa Helena Anzolina, Rosa Lydia Teixeira Corrêa ${ }^{b}$ \\ a Mestranda do Programa de Pós-Graduação em Educação da PUCPR e Coordenadora \\ do Sistema Integrado de Bibliotecas da PUCPR. Curitiba, PR - Brasil, e-mail: \\ heloisa.anzolin@pucpr.br \\ b Professora Doutora do Programa de Pós-Graduação em Educação da PUCPR. Curitiba, \\ PR - Brasil, e-mail: rosa.correa@pucpr.br
}

\begin{abstract}
Resumo
Neste trabalho analisamos como se dá a produção de conhecimento na universidade, por meio de professores-pesquisadores que participam de Grupos de Pesquisa, e daqueles que atuam apenas em sala de aula, e alunos-PIBIC em uma instituição de ensino superior. Essas três categorias de sujeitos estão sendo investigadas a partir do uso de serviços/produtos da Biblioteca universitária que se caracteriza como centro difusor de cultura e saber acumulado através do tempo. Estuda como se dá a relação entre Biblioteca e Conhecimento e, consequentemente, como ela contribui para a produção cientifica e atuação docente na universidade. Uma das funções da universidade é ser um espaço que permite o despertar para o pensamento crítico, o que pode ser feito tanto por meio do ensino quanto da pesquisa. O esforço empreendido nesta investigação foi para responder ao problema que integra uma investigação em nível de mestrado, qual seja: a Biblioteca universitária como centro difusor do saber, tem contribuído para a
\end{abstract}

Rev. Diálogo Educ., Curitiba, v. 8, n. 25, p. 801-817, set./dez. 2008 
atuação docente e para pesquisa? As respostas dos sujeitos apontam para a afirmativa de que, a Biblioteca está sim contribuindo para a produção de conhecimento, por meio das diversas possibilidades de acesso a informação que disponibiliza além de serviços/produtos oferecidos a comunidade acadêmica da IES.

Palavras-chave: Universidade; Conhecimento; Professores; Pesquisa; Biblioteca universitária.

\section{Abstract}

This work aims at analyzing the manner the production of knowledge takes place at the university, through research professors who have participated in Research Groups and through those professors who just teach in classrooms and PIBIC students in a higher learning institution. These three categories are being investigated based on the use of services/ products available at university libraries, which epitomize the center for culture and knowledge accrued through time. This work examines the relationship between the library and knowledge, and therefore, how it contributes to scientific production and faculty performance at the university. One of the functions of the university is to be a space that enables students to awaken to critical thinking, which may be brought about either through teaching or through research. The effort spent in this investigation was in order to answer the question that is part of an investigation at the master's degree level, which is the following: has the university library, as a center for spreading knowledge, contributed to faculty teaching and research? The answers of the interviewed point to an affirmative answer, which says that the Library is in fact contributing to the production of knowledge by opening up various possibilities of access to information and by making available services and products to the IES academic community.

Keywords: University; Knowledge; Professors; Research; University library. 
Biblioteca universitária como mediadora na produção de conhecimento 803

\section{INTRODUÇÃO}

Uma das funções da universidade é ser um espaço que possibilita o despertar do pensamento crítico por meio do conhecimento dali advindo. Esse tipo de pensar pode levar à produção de novo conhecimento a ser difundido. As universidades, de acordo com Oliveira (2002), caracterizam-se pela oferta regular de atividades de ensino de graduação, pesquisa e extensão, devendo manter programas de mestrado e/ou de doutorado em nível de pós-graduação.

Desde tempos remotos, a universidade sempre teve por fim cultivar e transmitir o saber humano acumulado, missão que ela tem cumprido com persistência (WANDERLEY, 1983, p. 37). De acordo com Rodrigues Júnior et al. (2000), a universidade teve, por um longo período de sua história, como única função a transmissão do conhecimento, o ensinar, mas a partir do século XIX incorporou a atividade de pesquisa no ambiente acadêmico.

Fazer pesquisa é fazer ciência, ela que:

Como modalidade de conhecimento, só se processa como resultado de articulação do lógico com o real, do teórico com o empírico. Não se reduz a mero levantamento e exposição de fatos ou a uma coleção de dados. Estes precisam ser articulados mediante uma leitura teórica. Só a teoria pode caracterizar como científicos dados empíricos. Mas, em compensação ela só gera ciência se tiver articulando dados empíricos. (SEVERINO, 2002, p. 70).

Nesse sentido, a atividade de pesquisa que significa operar no campo científico, requer buscar respostas às indagações que formulamos ao objeto de pesquisa que temos como propósito investigar no sentido, digamos, de decifrá-lo levando em conta um exercício interpretativo. Trata-se de um fazer que requer ser minucioso e criterioso com vistas ao devido aprofundamento sobre aquilo que se investiga. Por isso, a Biblioteca universitária é imprescindível como suporte à infraestrutura bibliográfica e documental a qualquer comunidade acadêmica, é indispensável no processo de pesquisa, estudo e consequente produção de conhecimento.

Sendo assim, pretende-se, neste trabalho, trazer alguns dados referentes à relação Biblioteca e conhecimento a partir de alguns depoimentos de professores e alunos-PIBIC como parte do questionamento que orienta uma pesquisa em nível de mestrado, qual seja: a Biblioteca universitária como centro difusor do saber, tem contribuído para a atuação docente quer em termos de ensino e de pesquisa? Deste modo além de analisarmos os primeiros dados empíricos no sentido de responder a essa indagação, estaremos situando resumidamente a Biblioteca universitária no panorama histórico da universidade.

Rev. Diálogo Educ., Curitiba, v. 8, n. 25, p. 801-817, set./dez. 2008 
Analisamos o uso de recursos e serviços informacionais da Biblioteca com vistas à produção de conhecimento científico e melhoria do ensino a partir dos dados obtidos de professores-pesquisadores e daqueles que exercem somente a docência, além dos alunos-PIBIC que estão iniciando na pesquisa científica.

\section{Conhecimento: retomada histórica}

O conhecimento desde a Antiguidade passou por uma série de fases caracterizadas por idéias acerca do mundo. Assim, resgatando a história social do conhecimento na Europa moderna ele foi classificado por grupos diferentes de maneiras também diferentes. Uma distinção recorrente era feita entre conhecimento teórico e o conhecimento prático, o conhecimento dos filósofos e o dos empíricos, Ciência (scientia) e Arte (ars). Distinção também entre conhecimento público e privado. Privado no sentido de restrito a um grupo particular da elite. Já em relação ao conhecimento público gerava controvérsia e respondia de maneira diferente por diferentes gerações. Esse conhecimento também passou pela censura de textos, como por exemplo, a Biblia. A confiabilidade também foi questionada por diferentes culturas e em diferentes períodos, o objetivo de saber tudo sobre tudo foi um ideal perseguido (BURKE, 2003).

Nos períodos (Séc. V ao Séc. X - Alta Idade Média e do Séc. XI ao Séc. XV - Baixa Idade Média) o conhecimento era privilégio de poucos. Hoje ainda o é, principalmente do ponto de vista científico.

É no século XIX que se cria o termo ciência ${ }^{1}$ em seu sentido moderno. E a palavra cientista passa a ser usada para nomear aqueles que se dedicam a estudos específicos. A ciência passa a influenciar desde a mudança de currículo das escolas até o desenvolvimento das nações (quem não tivesse uma boa ciência, como até hoje, perde o trem da História). Mas a ciência que parecia um corpo de conhecimentos quase prontos e acabados passou ainda por sérias transformações no século XX (ALFONSO-GOLDFARB, 1994).

O conhecimento passa por diversas fases de desenvolvimento ao longo da História, novas teorias e descobertas surgem e vão contribuindo para a transformação da sociedade em seus diferentes aspectos. Os meios de comunicação, entre eles o livro e a tecnologia da informação tem uma participação importante para a democratização do conhecimento, principalmente com o advento da internet, que é uma fonte inesgotável de informação. Neste sentido, a aquisição da informação não passa somente pelas escolas e universidades. Atualmente, qualquer pessoa pode

Conjunto organizado de conhecimentos relativos a um determinado objeto, especialmente os obtidos mediante a observação, a experiência dos fatos e um método próprio (FERREIRA, A. B. H. Novo dicionário da língua portuguesa. Rio de Janeiro: Nova Fronteira, 1986.

Rev. Diálogo Educ., Curitiba, v. 8, n. 25, p. 801-817, set./dez. 2008 
Biblioteca universitária como mediadora na produção de conhecimento 805

informar-se sobre o que tiver interesse acessando a internet de seu computador em casa e em locais apropriados para os que não possuem computador doméstico. Sendo a Biblioteca um desses locais, que além de disponibilizar coleções impressas, em sua grande maioria, disponibilizam computadores para acesso a internet.

\section{Biblioteca e conhecimento}

O volume de informação produzido no mundo atualmente e que circula em todos os canais disponíveis, é simplesmente inimaginável. Essa quantidade de informações vem desafiando tanto aqueles que precisam encontrálas quanto os encarregados de selecioná-las e organizá-las. Quanto mais informação está a nosso dispor, mais difícil e demorado é para chegar exatamente na informação desejada. Por esta razão hoje, e cada vez mais, a Biblioteca, por meio de seu acervo, é mais exigida no sentido de responder, de um lado, às crescentes exigências de atualização, e, de outro, às demandas geradas pela produção do conhecimento, por meio da pesquisa de natureza científica.

Os professores-pesquisadores necessitam ter conhecimento do que já foi ou está sendo pesquisado sobre o tema de interesse por outros grupos. Neste contexto entra o bibliotecário, procurando, selecionando e disseminando a informação, ou seja, oferecendo serviços com eficiência e rapidez para a comunidade científica. Conforme Milanesi $(1998$, p. 72$)$ a universidade e a Biblioteca refletem-se. Uma medida da qualidade de uma instituição de ensino superior é a excelência de sua Biblioteca. A Biblioteca de uma universidade deve ser considerada como uma "enciclopédia" viva do mundo moderno. Funciona como um centro de armazenamento e classificação do saber acumulado da humanidade e de irradiação de informação e das variadas formas de cultura (JULIATTO, 1998, p. 105).

A compreensão da Biblioteca da universidade não pode dar-se fora do processo histórico que assinala o surgimento das universidades e das Bibliotecas no mundo, ainda que para isso tenhamos que proceder a uma breve retomada histórica nesse sentido. Este é um primeiro aspecto que consideramos importante na realização deste estudo.

O berço da cultura dos novos tempos encontra-se, como sempre, nas cidades. É nelas que surgiram as instituições que, em alguns casos, preservaram suas origens medievais até hoje: as universidades. As que ficaram mais conhecidas situavam-se em Paris, Oxford, Cambridge, Pádua e Praga. Nelas, aprendiam-se as sete artes liberais: o trivium (gramática, lógica e retórica) e o quadrivium (geometria, astronomia, aritmética e música). Além das especialidades: direito, medicina, teologia e a filosofia (SCHWANITZ, 2007).

Rev. Diálogo Educ., Curitiba, v. 8, n. 25, p. 801-817, set./dez. 2008 
As universidades, historicamente, surgem ligadas a Igreja, com acesso restrito para poucos intelectuais. As Bibliotecas, consequentemente, estavam ligadas as universidades e mosteiros. As Bibliotecas monásticas, por um longo período, foram os locais onde o conhecimento permaneceu guardado, sendo que determinados textos, como a Bíblia, eram considerados sagrados e, portanto, seu acesso era restrito a poucos.

A censura e o controle de acesso aos textos escritos predominaram no mundo antigo. Mas além da censura, também havia muitos furtos de livros na Idade Média e Renascença. No mundo atual, acorre justamente o contrário, a informação está praticamente toda disponível para consulta em Bibliotecas ou centros de documentação, onde o acesso as estantes é livre, sem falar dos documentos que estão disponíveis na rede mundial de computadores, com texto completo. O que ocorre hoje é, talvez, um grande problema para a civilização pós-moderna porque se tornou impossível saber tudo que está sendo publicado sobre determinado assunto no mundo. Muito embora o acesso a essas informações ainda continue não disponível de forma igualitária para todos.

A Biblioteca desde o seu surgimento até o final da Idade Média persistia em conservar a idéia de depósito de livros, exatamente o que a palavra Biblioteca significa, "é mais o lugar onde se esconde o livro do que o lugar de onde se procura fazê-lo circular ou perpetuá-lo. A própria disposição arquitetônica dos edifícios demonstra" (MARTINS, 2002, p. 21-71).

No século XIX e início do século XX, surgem as grandes Bibliotecas no mundo, com acervos enormes de coleções de livros. Prédios foram construídos para abrigar esses acervos, havendo necessidade de organização de todo o material para disponibilizá-lo ao público. As Bibliotecas passam de acesso fechado, que era comum até então, para "livre acesso às estantes". O que foi um avanço porque oferece a possibilidade ao leitor de escolher pessoalmente os livros, de examinar e folhear a vontade (MARTINS, 2002, p. 328).

As Bibliotecas, devido às condições específicas como a fragmentação do conhecimento, e também, a impossibilidade espacial e financeira de reunir em um único espaço toda a informação registrada disponível, são divididas em vários tipos, como: universitárias, públicas, especializadas, escolares, infantis, a exemplo. Cada uma delas com características específicas de acordo com o público e comunidade a que serve.

Em meados do século XX, as mudanças sociais aliadas à progressiva expansão e fragmentação do conhecimento, bem como o avanço tecnológico levam a outra fase de evolução em que a preocupação com o "tipo" de Biblioteca até então posto em uso, um sistema independente de origem institucional, um padrão de serviços acessível, todo o potencial dos serviços dispostos aos utilizadores potenciais, tende a desaparecer. Este padrão seria substituído por uma grande

Rev. Diálogo Educ., Curitiba, v. 8, n. 25, p. 801-817, set./dez. 2008 
Biblioteca universitária como mediadora na produção de conhecimento 807

diversificação dos serviços e produtos; e também pela diversificação dos suportes informacionais disponíveis. As palavras de ordem nesse período são: flexibilidade, adaptabilidade, interdependência e cooperação. No final desse século surge uma nova configuração de Bibliotecas, as virtuais/digitais.

No século XXI, as Bibliotecas virtuais/digitais são uma realidade indiscutível. Entramos na chamada era virtual, que Browning (2002) chamou de "Bibliotecas sem paredes para livros sem páginas". Uma quantidade inimaginável de informação está à disposição no ciberespaço. $\mathrm{O}$ acesso a informação tornouse mais democrático, por meio do uso das tecnologias da informação e comunicação, que tem uma participação decisiva nas mudanças ocorridas na sociedade em geral. Não poderia ser diferente nas universidades e suas Bibliotecas. Assim, nas Bibliotecas, consequentemente, essas mudanças são visíveis na forma de atuação e prestação de serviços.

A Biblioteca sempre esteve ligada à idéia de universidade por ser esta historicamente um centro produtor e difusor de conhecimento. Por essa razão importa que procedamos a uma pequena apreciação sobre conhecimento com o fito de indicarmos em que sentido o entendemos neste estudo.

Conceituar conhecimento se faz necessário à medida que a universidade, por meio do ensino e pesquisa, está diretamente relacionada à sua transmissão, preservação, criação e difusão. É o locus que permite seu desenvolvimento, tanto científico quanto humano. Nenhum saber se origina do nada; mas também nenhum saber se faz na mera "transmissão do já sabido" (MARQUES, 2003). A universidade não apenas repassa o conhecimento, mas o toma como ponto de partida para a geração de um novo conhecimento.

A palavra conhecimento encerra uma complexidade que dificulta chegar a uma definição precisa sobre seu significado. Com efeito, Ferreira (1986) apresenta várias definições, tais como: "prática de vida; consciência de si mesmo; apropriação do objeto pelo pensamento, como quer que se conceba essa apropriação: como definição, como percepção clara, apreensão completa, análise, etc." Desta compreensão podemos tomar as idéias de "apropriação do objeto pelo pensamento, como quer que se conceba essa apropriação", justamente no sentido que acima nos referimos quando falamos de pesquisa e, sem dúvida, o entendimento de análise, imprescindível a qualquer relação acadêmica com o conhecimento.

O Glossário da Sociedade da Informação (2005) traz a definição de conhecimento como "um conjunto de noções e de princípios que uma pessoa adquire pelo estudo, observação ou experiência e que pode integrar nas suas capacitações ou ainda coleção de fatos e acontecimentos, crenças e regras, organizadas para uso sistemático.”

Rev. Diálogo Educ., Curitiba, v. 8, n. 25, p. 801-817, set./dez. 2008 
No entanto, para Setzer (1999) "conhecimento é uma abstração interior, pessoal, de alguma coisa que foi experimentada por alguém", e completa que está "associado com pragmática, isto é, relaciona-se com alguma coisa existente no 'mundo real' do qual temos uma experiência direta."

Como se pode observar uma das definições do termo conhecimento, segundo Ferreira (1986), refere-se à apropriação do objeto pelo pensamento, operase a nível cognitivo, tácito, com a faculdade de perceber, compreender e interpretar. A definição do Glossário da Sociedade do Conhecimento (2005) coloca que conhecimento são noções e princípios que podem ser adquiridos por observação e estudo, podendo integrando-se como capacitação pessoal, ou ainda, experiência pessoal, incluindo aqui consciência de si mesmo e prática de vida, citado também em Ferreira (1986). A definição de Setzer (1999) comunga com a idéia de conhecimento como experimentação de algo vivido ou observado, também em nível cognitivo. A segunda definição do Glossário da Sociedade do Conhecimento (2005) trata o termo conhecimento como fatos e acontecimentos, crenças e regras, ou seja, a vida cotidiana de uma pessoa, organizado para uso sistemático, para aplicá-lo no convívio em sociedade. Este sentido o restringe bastante.

Neste ponto, se pode presumir que conhecimento é toda manifestação de algo que se dá em nível cognitivo, advindo de experiência de vida ou estudo, podendo ser organizado para desenvolvimento pessoal.

Assumimos o conceito de conhecimento como sendo: "conjunto de noções e de princípios que uma pessoa adquire pelo estudo, observação ou experiência e que pode integrar nas suas capacitações." O conhecimento é, ao mesmo tempo, atividade (cognição) e produto dessa atividade [...]. Todo conhecimento é vivo, o conhecimento humano é um conhecimento de um indivíduo ao mesmo tempo produto e produtor, [...] é ao mesmo tempo subjetivo e objetivo (MORIN, 2005, p. 224-225). Neste particular, trata-se de um modo de conhecimento específico: o científico, fruto do estudo da reflexão, observação e comparação criteriosa, como assinalamos acima.

Ao se falar em conhecimento, vale dizer, que o mesmo pode se manifestar de várias formas na literatura, como: conhecimento popular ou senso comum; conhecimento filosófico; conhecimento religioso ou teológico; conhecimento artístico ou estético e conhecimento científico. Essas formas de conhecimentos remetem a seguinte indagação: de que tipo de conhecimento tratamos neste estudo? Sem dúvida, do conhecimento científico já que ele está no centro do fazer universitário. É em torno deste que alunos e professores, e que a instituição universitária, se organizam e criam uma dinâmica própria.

O conhecimento científico é a transformação em saber científico do que está no senso comum. Não é mais ou menos importante do que as outras formas de conhecimento para a humanidade, mas pode-se dizer que é uma forma privilegiada, segundo o pensamento de Boaventura Sousa Santos em sua fala:

Rev. Diálogo Educ., Curitiba, v. 8, n. 25, p. 801-817, set./dez. 2008 
Biblioteca universitária como mediadora na produção de conhecimento 809

O conhecimento cientifico é hoje a forma oficialmente privilegiada de conhecimento e a sua importância para a vida das sociedades contemporâneas não oferece contestação. Na medida das possibilidades, todos os países se dedicam à promoção da ciência, esperando benefícios do investimento nela. (SANTOS, 2006, p. 17).

\section{Sobre a pesquisa}

Este trabalho se caracteriza como um estudo de caso. O caso estudado foi a Biblioteca universitária e sua contribuição para a produção científica, em uma IES de renome no Paraná, com diversos programas de pós-graduação stricto sensu e com o programa para iniciação científica/PIBIC institucionalizado desde 1992. Além disso, a IES está entre as melhores instituições de ensino superior privada de pesquisa no cenário nacional (IES, 2006). O que a priori a qualifica para o estudo.

O estudo de caso é uma das maneiras possíveis de realizar pesquisa social e "representa a estratégia preferida quando se colocam questões do tipo "com" e "por que", quando o pesquisador tem pouco controle sobre os eventos e quando o foco se encontra em fenômenos contemporâneos inseridos em algum contexto da vida real" (YIN, 2001, p. 1). "O estudo de caso é uma categoria de pesquisa cujo objetivo é a unidade que se analisa profundamente" (TRIVIÑOS, 1987, p. 133). De acordo com Chizzotti (2003, p. 102) o estudo de caso é:

Uma caracterização abrangente para designar uma diversidade de pesquisas que coletam e registram dados de um caso particular ou de vários casos a fim de organizar um relatório ordenado e crítico de uma experiência, ou avaliá-la analiticamente, objetivando tomar decisões a seu respeito ou propor uma ação transformadora.

O tipo de pesquisa que será utilizada é a qualitativa, que descreve e analisa a complexidade de um problema real. Segundo Minayo (2000, p. 21-22):

A pesquisa qualitativa responde a questões muito particulares. Ela se preocupa, nas ciências sociais, com um nível de realidade que não pode ser quantificado. Ou seja, ela trabalha com universo de significados, motivos, aspirações, crenças, valores e atitudes, o que corresponde a um espaço mais profundo das relações, dos processos e dos fenômenos que não podem ser reduzidos à operacionalização de variáveis.

Rev. Diálogo Educ., Curitiba, v. 8, n. 25, p. 801-817, set./dez. 2008 
O campo de pesquisa foi delimitado em torno da comunidade acadêmica da universidade. Os participantes da pesquisa foram selecionados dentro do universo de professores cuja atuação se dá somente em sala de aula na graduação, e professores-pesquisadores integrantes de Grupos de Pesquisa da instituição, com atuação na graduação e pós-graduação. Além dos professores, fazem parte da pesquisa alunos envolvidos em Programa Institucional de Bolsa de Iniciação Científica-PIBIC.

Selecionamos como participantes dois professores e 2 alunos-PIBIC de cada área do conhecimento, ou seja, humanas, saúde, jurídicas e sociais e ciências sociais aplicadas. Inicialmente foram levantados os nomes, do que passaremos a denominar de professores e professores-pesquisadores junto ao cadastro institucional da Universidade e posteriormente procedemos a um levantamento da produção científica dos participantes no Currículo Lattes.

Os critérios adotados para selecioná-los foram: professores com formação em latu sensu não envolvidos em grupos de pesquisas e professorespesquisadores (especialistas, mestres e doutores) com produção científica. Para os alunos-PIBIC os que tiveram seus trabalhos incluídos nos Cadernos de Resumos de Seminários de Iniciação Científica da IES.

O questionário foi divido em duas partes, sendo uma com três perguntas fechadas e o outra com três questões abertas. Responderam-no um total de cinco professores.

Nas questões fechadas solicitamos aos sujeitos da pesquisa que indicassem o uso da Biblioteca e os serviços e produtos oferecidos pela mesma utilizados por eles. Também perguntamos sobre o uso dos espaços físicos disponíveis para atividades específicas, como, por exemplo, Laboratório de Acessibilidade, ${ }^{2}$ Cabines de vídeo, Cabines para trabalhos em grupo, etc. Nas questões abertas, o participante informou como desenvolve um novo projeto de pesquisa na universidade, ou, um novo Programa de Aprendizagem ${ }^{3}$ em relação à bibliografia necessária para sua atuação profissional.

\section{O que dizem os professores}

As respostas obtidas nas questões fechadas sobre o uso do acervo e serviços da Biblioteca mostram que: os professores frequentam a Biblioteca no mínimo uma vez por semana. O acesso a publicações por meio da Biblioteca Virtual (que

2 Sala especialmente adaptada para uso de pessoas portadoras de necessidades educativas especiais; como, cegos, baixa visão, cadeirantes temporários ou definitivos, deficientes auditivos.

3 São denominados Programas de Aprendizagem os Programas das disciplinas desenvolvidas nos diferentes cursos ofertados pela Universidade.

Rev. Diálogo Educ., Curitiba, v. 8, n. 25, p. 801-817, set./dez. 2008 
Biblioteca universitária como mediadora na produção de conhecimento 81

disponibiliza periódicos, na sua grande maioria, com texto na íntegra e E-Books), foi praticamente uma unanimidade de uso. Dos cinco professores que responderam ao questionário quatro disseram que este serviço é bastante utilizado pelos mesmos.

O serviço de Normas para Trabalhos Científicos, disponíveis no site da Biblioteca, se mostrou uma unanimidade entre os cinco professores, onde dizem que além de utilizarem, também indicam aos seus alunos e justificam que, é uma boa fonte de consulta rápida sobre a normalização de trabalhos (PROFESSOR 2). A afirmação que "é prático" e a "disponibilidade facilita nos momentos de dívida" (PROFESSOR 3), e ainda que "é a norma de nosso curso" aparece na fala do PROFESSOR 4.

Empréstimo domiciliar e consulta local a livros, periódicos impressos, fitas de vídeo, dvds e outros multimeios, mostrou-se pouco utilizado pelos professores. Dos cinco professores que responderam ao questionário três disseram que pouco usam esses recursos. Alguns serviços como, catalogação na fonte, serviço de malote entre Câmpus, empréstimo entre Bibliotecas não são usados por nenhum dos participantes. A existência e finalidade do Laboratório de Acessibilidade é desconhecida por praticamente todos os professores que responderam os questionários. Dos cinco respondentes, os cinco disseram não usar esse meio de acesso ao conhecimento.

Perguntados como vem à relação entre Biblioteca e Conhecimento na Universidade, tivemos as seguintes respostas: essencial, fundamental, de grande apoio e facilitadora do acesso ao conbecimento produzido. Sistematização e organização do material produzido, em suas diferentes formas (PROFESSOR 3).

A resposta é vaga indicando que o entrevistado não usa a Biblioteca como meio de pesquisa. Embora veja a relação entre Biblioteca e Conhecimento como essencial, o que parece óbvio, não aprofunda essa apreciação, principalmente no que pese à produção de conhecimento. Nesse sentido, não parece ser vista como meio que contribua para a produção de conhecimento. A expressão facilitadora do acesso ao conbecimento produzido, aparece na fala do professor, demonstrando o entendimento sobremaneira mecânico dessa relação.

Por outro lado, na resposta a seguir, o professor menciona a internet como meio de acesso ao conhecimento, pela sua facilidade. O que não tira da Biblioteca sua função maior segundo ele, de espaço para reflexão e acesso à informação. Informação essa que poderá ser transformada em conhecimento e transmitida, por meio da produção cientifica da comunidade acadêmica. Chama atenção o caráter de sabedoria atribuído à biblioteca. Percebe-se que embora possua esse entendimento sobre a internet não retira da Biblioteca o valor que possui.

Faço minhas as palavras escritas na placa inaugural da Biblioteca Central, "a sabedoria construiu para si uma morada". Penso que a Biblioteca e Conhecimento são coisas indissociáveis, muito embora a utilização da Internet tenha ganhado corpo, especialmente pela

Rev. Diálogo Educ., Curitiba, v. 8, n. 25, p. 801-817, set./dez. 2008 
facilidade e não linearidade da pesquisa. Ainda assim, a Biblioteca é o espaço de calma e silenciosa reflexão. Nem que seja apenas para um passeio por entre as prateleiras e uma descompromissada procura por "aquela" referência bibliográfica que fará toda a diferença num trabalho, monografia, dissertação ou tese. (PROFESSOR 2).

No entanto, a fala seguinte sugere que esse professor demonstra ter clareza sobre a relação entre Biblioteca e Conhecimento na Universidade. Quando afirma que: "[...] Biblioteca perde um pouco o papel de local de pesquisa, mas ganha um papel de centralizador do processo de pesquisa, interconectando as diversas bases [...]", mostra a que a novas tecnologias da informação e comunicação, transformaram a visão da Biblioteca antiga, de guardiã, ou depósito de livros. Hoje, ela significa bem mais que isso. Podemos dizer que ela contribui para a reflexão necessária à produção do conhecimento por meio da pesquisa.

A biblioteca é um dos elementos fundamentais na transmissão do conhecimento, ao permitir aos estudantes e pesquisadores acesso ao conhecimento desenvolvido no passado. Hoje, com as modernas tecnologias de informação, permite mais do que isto, ao possibilitar não só o acesso, mas principalmente o filtro e seleção do material por palavras-chave, sem o qual o processo de pesquisa e localização dos livros e artigos seriam muito mais demorados e ineficientes. Neste sentido, a biblioteca perde um pouco o papel de local de pesquisa, mas ganha um papel de centralizador do processo de pesquisa, interconectando as diversas bases e permitindo uma flexibilidade maior no acesso à informação. Por outro lado, ainda é importante como um espaço devotado ao estudo ao permitir os estudiosos um espaço onde possam esquecer o mundo e se concentrar no foco de estudo, possibilitando uma cápsula de proteção e isolamento para permitir um mergulho mais profundo na matéria em estudo. (PROFESSOR 1).

Fica, pois, claro que o espaço físico da Biblioteca com todo seu significado, como centro difusor do saber, da cultura, ou apenas para um trabalho acadêmico, ainda é um espaço privilegiado dentro da universidade para produção do conhecimento. No depoimento acima podemos constatar o entendimento sobre a Biblioteca como mediadora seja do ensino, seja da pesquisa, ao conectar-se também com outros meios tecnológicos de acesso ao conhecimento. Espaço de estudo, de concentração, de recolhimento, necessários ao estudo e à descoberta.

Finalmente, ainda permanece a concepção de Biblioteca e sua relação com o conhecimento produzido no passado. Parece haver aqui um sentido de história exclusivamente como algo que já foi e não está sendo.

Rev. Diálogo Educ., Curitiba, v. 8, n. 25, p. 801-817, set./dez. 2008 
Biblioteca universitária como mediadora na produção de conhecimento 813

\title{
O que dizem os alunos
}

A percepção dos alunos-PIBIC em relação à biblioteca e conhecimento é mostrada nas falas selecionadas.

Os alunos sabem, claramente, que a biblioteca é uma fonte de informação indispensável à produção de conhecimento na universidade. Mas a avaliação deles gira em torno da quantidade de livros e periódicos que ela disponibiliza. O que nos leva novamente a recorrer a História da Biblioteca, que nasceu da necessidade de abrigar e organizar coleções de obras impressas. Essa visão ainda predomina sobre a Biblioteca, embora atualmente ela ofereça outras fontes de informação com vídeos, dvds, etc, como centro cultural ou de lazer.

\begin{abstract}
A Biblioteca apresenta um rico acervo bibliográfico capaz de fornecer uma base inicial para a pesquisa cientifica (revisão de literatura). Dessa foram, é possivel saber o que já foi feito em relação à área de interesse, qual a visão de outros autores a respeito, entre outras informações importantes. A meu ver a forma mais rica de estabelecer uma base teórica sobre determinado assunto é a leitura de livros a ele relacionados. A Biblioteca, ainda, possui a marca da interdisciplinaridade. Possui obras com as mais variadas ópticas, oriundas das mais diversas áreas de atuação, contando com inúmeros assuntos de interesse. Isso é fundamental para ampliar horizontes pessoais através da cultura. (ALUNO-PIBIC 8).
\end{abstract}

Nesta fala o aluno considera que essa relação deve ser buscada pelo aluno assim como pelo professor, mas que o professor deve estar orientado e incentivando o aluno.

A relação entre Biblioteca e conhecimento na universidade depende exclusivamente do interesse do aluno, uma vez que este é o principal interessado em aprender e obter conhecimento. A busca incessante pelo aprendizado não é só tarefa do professor, pois este tem a função de orientar e difundir seu conhecimento, orientando o aluno onde conseguir mais informações na Biblioteca. (ALUNO-PIBIC 10).

Uma relação de dependência e mutualidade. Apesar dos sites técnicoinstitucionais existentes para a busca de informaçôes científicas, nada pode substituir o valor intelectual que os serviços e materiais existentes em uma Biblioteca agregam ao conbecimento e ao desenvolvimento do trabalho científico. É possivel afirmar que o conbecimento na Universidade é diretamente proporcional à riqueza do acervo, estrutura

Rev. Diálogo Educ., Curitiba, v. 8, n. 25, p. 801-817, set./dez. 2008 
e serviços disponíveis em sua Biblioteca. Ademais, a organização da base de dados e do acervo bem como a quantidade de exemplares existentes viabiliza maior acesso das pessoas ao acervo e, portanto, ao conhecimento. (ALUNO-PIBIC 2).

$\mathrm{Na}$ fala que segue o aluno demonstra surpresa ao responder o questionário e ao perceber que não tinha conhecimento das possibilidades que a biblioteca oferece e conclui que não a explorou como poderia, inclusive para sua atividade de iniciação à pesquisa.

Quando comecei a responder este questionário achei que conbecia a Biblioteca da Universidade. Portanto acho que a cultura de utilização deste serviço, no meu caso, não faz parte do dia-a-dia da pesquisa. Entendo sim a Biblioteca como uma poderosa ferramenta de difusão do conbecimento, no entanto, pouco explorada. (ALUNO-PIBIC 9).

Esta fala demonstra que o aluno precisa ser incentivado e motivado ao uso da Biblioteca, pela necessidade de aprofundamento do tema da pesquisa. O desconhecimento dos serviços/produtos da Biblioteca pode sugerir que os mesmos precisam ser mais divulgados. Outra hipótese possível é que o alunoPIBIC entre no programa apenas para conseguir a bolsa com ajuda financeira e que não tenha perfil para a pesquisa, e nesse caso, irá fazer apenas o que lhe for cobrado. Trabalhar com pesquisa exige uma nova postura do aluno, que deixa de ser objeto de ensino para ser parceiro de trabalho (DEMO, 2000).

Para desenvolver o espírito investigativo precisa de certo tempo na atividade, o que no caso dos alunos-PIBIC incluídos na pesquisa não aconteceu, porque $70 \%$ permaneceram apenas um ano no programa.

\section{CONSIDERAÇÕES FINAIS}

As respostas obtidas apontam que, a Biblioteca no entendimento dos sujeitos das três categorias pesquisadas está subliminarmente contribuindo para a produção científica dos professores-pesquisadores, alunos-PIBIC e atuação docente. Essa contribuição se dá a partir de seu acervo armazenado localmente, e também por acesso a milhares de títulos de periódicos disponibilizados em sua Biblioteca Virtual, na Biblioteca Digital por meio da produção científica da IES. Além de outros serviços/produtos como ficou comprovado nos resultados da pesquisa, por exemplo, orientação à

Rev. Diálogo Educ., Curitiba, v. 8, n. 25, p. 801-817, set./dez. 2008 
Biblioteca universitária como mediadora na produção de conhecimento 815

normalização para trabalhos científicos, dentre outros. No caso de empréstimo domiciliar, ficou demonstrado nas respostas não ser muito utilizado por parte dos professores e professores-pesquisadores, provavelmente pelo uso de Biblioteca particular.

Percebemos nas respostas dos docentes que os mesmos pensam à Biblioteca mais para fins de apoio aos conteúdos trabalhados em sala de aula. Já para os professores-pesquisadores, notamos que percebem a Biblioteca como mediadora entre a informação e produção de conhecimento. Os alunos-PIBIC em sua grande maioria utilizam e percebem a Biblioteca como um apoio à aquisição de conhecimento, mas ao mesmo tempo referem-se a ela como se seu acervo fosse formado apenas de livros. Utilizam os serviços de empréstimo de forma predominante e não exploram as muitas possibilidades de acesso ao conhecimento por meio da Biblioteca.

Cabe ressaltar, entretanto, que a contribuição da Biblioteca para a produção de conhecimento, não está totalmente visível por parte da comunidade pesquisada nesse estudo. Sabemos que essa percepção pode e deve ser ampliada por meio de ações que podem ser implementadas conjuntamente por bibliotecários e professores.

\section{REFERÊNCIAS}

ALFONSO-GOLDFARB, A. M. O que é história da ciência. São Paulo: Brasiliense, 1994. (Coleção primeiros passos; 286).

BROWNING, J. Libraries without walls for books without pages. 2002. Disponível em: <http://www.wired.com/wired/archive/ 1.libraries.hml>. Acesso em: 19 jan. 2007.

BURKE, P. Uma história social do conhecimento: de Gutenberg a Diderot. Rio de Janeiro: J. Zahar, 2003.

CHIZZOTTI, A. Pesquisa em ciências humanas e sociais. 6. ed. São Paulo: Cortez, 2003.

DEMO, P. Educar pela pesquisa. 4. ed. Campinas: Autores Associados, 2000.

FERREIRA, A. B. H. Novo dicionário da língua portuguesa. Rio de Janeiro: Nova Fronteira, 1986.

GLOSSÁRIO da sociedade do conhecimento. Lisboa: APDSi, 2005.

Rev. Diálogo Educ., Curitiba, v. 8, n. 25, p. 801-817, set./dez. 2008 
INSTITUTO DE ENSINO SUPERIOR - IES. É a universidade privada que mais investe em pesquisa no Paraná. Vida universitária, v. 21, n. 167, p. 6, 2006.

JULIATTO, C. I. Pensando na biblioteca da universidade. Educação brasileira, v. 10, n. 21, p. 105-123, 1998.

MARQUES, M. O. Escrita e pesquisa na universidade. In: MARQUES, M. O. Escrever é preciso. 4. ed. Ijuí: Unijuí, 2003.

MARTINS, W. A palavra escrita: história do livro, da imprensa e da biblioteca. 3. ed. São Paulo: Ática, 2002.

MILANESI, L. O que é biblioteca. São Paulo: Brasiliense, 1998. (Coleção primeiros passos; 94).

MINAYO, M. C. de S. (Org.). Pesquisa social. Petrópolis, RJ: Vozes, 2000.

MORIN, E. O método 3: o conhecimento do conhecimento. 3. ed. Porto Alegre: Sulina, 2005.

OLIVEIRA, N. M. de. A biblioteca das instituições de ensino superior e os padrões de qualidade do MEC: uma análise preliminar. Perspectivas em ciência da informação, v. 7, n. 2, p. 207-221, jul./dez. 2002.

RODRIGUES JÚNIOR, J. M. et al. Produção do conhecimento tecnológico na UFMG. Perspectivas em Ciência da Informação, v. 5 , n. 2, p. 231-242, jul./dez. 2000.

SANTOS, B. S. (Org.). Conhecimento prudente para uma vida decente: um discurso sobre as ciências revisitado. 2. ed. São Paulo: Cortez, 2006.

SCHWANITZ, D. Cultura geral: tudo o que se deve saber. São Paulo: Martins Fontes, 2007.

SETZER, V. Dado, informação, conhecimento e competência. DataGramaZero - Revista de ciência da informação, n. 0, dez. 1999. Disponível em: <http://www.dgz.org.br/dez99?Art_01.htm>. Acesso em: 18 ago. 2006.

SEVERINO, A. J. Pós-Graduação e pesquisa: o processo de produção e de sistematização do conhecimento no campo educacional. In: BIANCHETTI, L.; MACHADO, A. M. (Org.). A bússola do escrever: desafios e estratégias de teses e dissertações. Florianópolis: UFSC, 2002. p. 67-108. 
Biblioteca universitária como mediadora na produção de conhecimento 817

TRIVIÑOS, A. N. S. Introdução à pesquisa em ciências sociais. São Paulo: Atlas, 1987.

WANDERLEY, L. E. W. O que é universidade. São Paulo: Brasiliense, 1983. (Coleção primeiros passos; 91).

YIN, R. K. Estudo de caso. 2. ed. Porto Alegre: Bookman, 2001.

Recebido: 14/02/2008

Received: $02 / 14 / 2008$

Aprovado: 01/07/2008

Approved: 07/01/2008

Rev. Diálogo Educ., Curitiba, v. 8, n. 25, p. 801-817, set./dez. 2008 